\title{
ON THE FREE RECOVERY BENDING SHAPE MEMORY EFFECT IN POWDER METALLURGY FeMnSiCrNi
}

\author{
Lenuța CIURC̆̆, Bogdan PRICOP, Mihai POPA, \\ Victor Daniel APOSTOL, Leandru-Gheorghe BUJOREANU*
}

Faculty of Materials Science and Engineering, „Gheorghe Asachi” Technical University of Iași, Blvd. Dimitrie Mangeron 61A. 700050 Iași, Romania

e-mail: leandru-gheorghe.bujoreanu@academic.tuiasi.ro

\begin{abstract}
This paper presents the results of an original experimental study on the training capacity of a powder metallurgy (PM) FeMnSiCrNi shape memory alloy (SMA). The specimens were sintered under protective atmosphere from blended elemental powders, 50 vol.\%. of alloy particles being mechanically alloyed. Lamellar specimens, hot rolled to $1 \mathrm{~mm}$ thickness, were bent against cylindrical calibres with five decreasing radii, to induce cold shapes with higher and higher deformation degree, as compared to the straight hot shape. During the training procedure, bent specimens were heated with a hot air gun, and developed freerecovery shape memory effect (SME) and partially deflected, by reducing their curvature. The first set of experiments involved fastening the specimens at one end, heating it and monitoring free end's displacement by means of cinematographic analysis. Within the second set of experiments, both cold and hot shapes were recorded and digitalized and their chord's length (b) and circle segment height (a) were measured and the radius was determined as $\mathrm{R}=\mathrm{a} / 2+\mathrm{b}^{2} / 8 \mathrm{a}$ for the cold $\left(\mathrm{R}_{\mathrm{c}}\right)$ and hot shapes $\left(\mathrm{R}_{\mathrm{h}}\right)$. Finally, the shape recovery degree was calculated for the $n^{\text {th }}$ calibre as $\Delta_{\text {recn }}=\left(R_{h}{ }^{n}-R_{r}{ }^{n}\right) /\left(R_{h}{ }^{n-1}-R_{r}{ }^{n}\right)$ and the variation of $\Delta_{\text {recn }}$ with calibre's radius was discussed.
\end{abstract} $\mathrm{FeMnSiCrNi}$

KEYWORDS: shape memory effect, training, shape recovery degree, PM

\section{Introduction}

Shape memory effect (SME) represents the most prominent characteristic of shape memory materials and consists in the recovery of a permanent (hot) shape, as an effect of applying a stimulus (e.g., heat, magnetic field, radiation, $\mathrm{pH}$ changing or water acceptance/rejection) to a material which has a temporary (cold) shape [1]. Shape memory materials include alloys, ceramics, polymers, composites and hydrides [2]. The first report on SME presence in alloys, refers to $\mathrm{Au}-\mathrm{Cd}$ system and has an age of seven decades [3]. The same alloy system was exhibited seven years later, for the 1958 Brussels Universal and International Exhibition, under the form of cylindrical single crystal $\varnothing 3 \times 10 \mathrm{~cm}$, which was martensitic at room temperature (RT), and represented the active part of a cyclic weight lifting device. The single crystal weighed approx. $10 \mathrm{~g}$ and had a $50 \mathrm{~g}$ weight fastened at its free end that bent it to a large extent. After heating, the cylinder became austenitic, therefore more strengthened and it lifted the load [4]. The list of alloy systems exhibiting SME rapidly increased with In-Tl (1953), Cu-Zn (1956), Cu-Al-Ni (1957), Ni-Ti (1963), Cu-Zn-Al (1970), Ti$\mathrm{Nb}$ (1971), Au-Cu-Zn (1971), Ni-Al (1971), Fe-Pt (1971), Cu-Zn-Sn (1972), Cu-Zn-Si (1972), Ag-Cd (1973), Cu-Sn (1973), Cu-Zn-Ga (1974), Ti-Pd-Ni (1982), Fe-Mn-Si (1982) [5], and more recently FeNi-Co-Al-Ta-B (2010) [6] and Fe-Mn-Al-Ni (2011) [7]. For each of these binary or ternary alloy systems, which have been finally designated as shape memory alloys (SMAs), quaternary, quintenary, etc. concentrations have been developed, by cumulating the beneficial effects of an increasing number of alloying elements.

Besides the above-mentioned alloy systems that are thermally activated, there is also an entire class of magnetically-driven SMAs [8] but their presentation falls beyond the scope of the present paper. 
In the specific case of Fe-Mn-Si SMAs, SME is based on thermally induced reversion to $\gamma$-face centered cubic (fcc) austenite of $\varepsilon$-hexagonal close packed (hcp) martensite which was stress induced when imprinting the temporary (cold) shape [9]. The development of Fe-Mn-Si based SMAs led to Fe-Mn$\mathrm{Si}-\mathrm{Cr}$ (1990) [10] and Fe-Mn-Si-Cr-Ni (1991) [11]. $\mathrm{Fe}-\mathrm{Mn}-\mathrm{Si}-\mathrm{Cr}-\mathrm{Ni} \mathrm{SMAs}$ are corrosion resistant and they are able to recover strains as large as $7.7 \%$ [12].

The most accessible method, for SME evaluation in straight lamellar specimens, consists in their progressive bending, at RT, against a small diameter cylindrical calibre and in subsequent heating. After measuring the bending $\left(\alpha_{\max }\right)$, the unloading ( $\alpha_{\text {cold }}<\alpha_{\max }$, since the specimen has a small spring back during unloading) and the heating angles ( $\alpha_{\text {hot }}<\alpha_{\text {cold }}$, since the specimens partially recover their straight) shape recovery degree is determined as $\Delta_{\text {rec }}=\left(\alpha_{\text {cold }}-\alpha_{\text {hot }}\right) / \alpha_{\text {cold }} \times 100$. Ideally, $\Delta_{\text {rec }}=100 \%$ if $\alpha_{\text {hot }}=0^{\circ}$ and the specimen completely recovered its straight shape [13].

As previously pointed out, powder metallurgy (PM) including mechanical alloying (MA) has the potential to represent an alternative processing technique for $\mathrm{Fe}-\mathrm{Mn}-\mathrm{Si}-\mathrm{Cr}-\mathrm{Ni}$ SMAs [14]. Nevertheless, in an Fe-Mn-Si-Cr-Ni SMA prepared by $\mathrm{PM}$ and containing 50 vol.\% of MA'ed powder, up to $32 \% \alpha$ ' - body centered cubic (bcc) martensite has been formed [15] which diminishes the magnitude of SME due to the obstruction of reverse martensitic transformation [16].
The present paper aims to investigate the training capacity of a powder metallurgy (PM) Fe$14 \mathrm{Mn}-6 \mathrm{Si}-9 \mathrm{Cr}-5 \mathrm{Ni}$ SMA with 50 vol.\%. of mechanically alloyed particles, when subjected to SME cycles.

\section{Experimental procedure}

Lamellar $(1 \times 10 \times 113 \mathrm{~mm})$ specimens have been cut by wire spark erosion from an Fe-14Mn-6Si9Cr-4Ni (wt.\%) SMA which was pressed, sintered, homogenized and hot-rolled as previously pointed out [17].

These specimens are rather fragile and must be plastically deformed with great care as to avoid cracking [18]. For this reason, the specimens were progressively bent, at RT, against cylindrical calibres with decreasing radii. When two calibres were used, the specimens were bent between them. When a single calibre was used the specimens were bent along its outer surface being fastened by a grip or it was bent into its inner surface. Figure 1 shows the five calibres used for the present experiments.

Figure 2 shows successive stages of cold shape inducing during training. It is noticeable that the specimens changed their hot (straight) shape, from Figure 2(a) to a clod (curved) shape, in Figure 2(g). If this shape was induced directly, from the straight shape, the specimen would definitely crack. Nevertheless, the cold shape radius is much larger than the radius of the last calibre $(18.4 \mathrm{~mm})$, due to material's spring back.

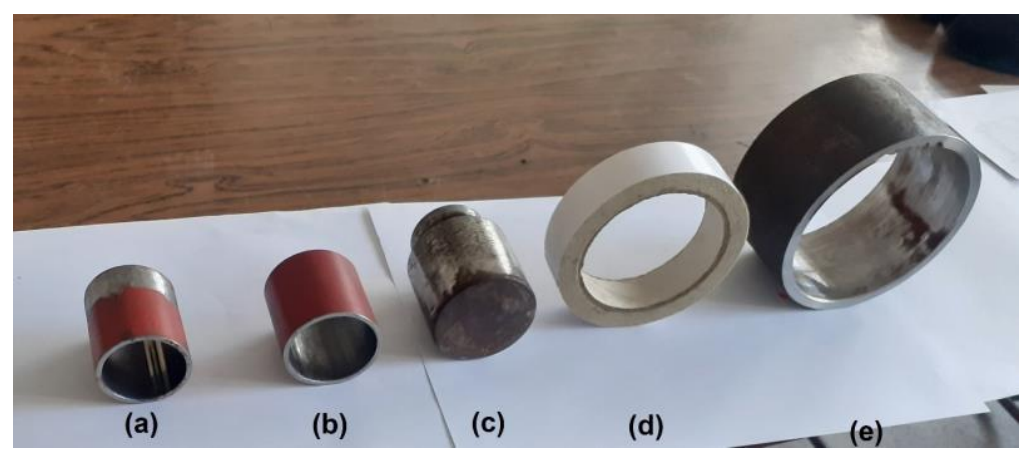

Fig. 1. Succession of radius-increasing calibers used for cold shape induction, with the following radii: (a) interior - $18.39 \mathrm{~mm}$ and exterior - $21.71 \mathrm{~mm}$; (b) interior - $24.4 \mathrm{~mm}$; (c) exterior - $27.8 \mathrm{~mm}$; (d) interior - $37.5 \mathrm{~mm}$ and (e) interior $-50 \mathrm{~mm}$

After inducing the cold shape, the specimens have been subjected to two types of training procedures, comprising the monitoring of: (i) free end's vertical displacement and (ii) curvature radius, during SME cycles (heating-cooling-deformation). Figure 3 illustrates two experimental stages of the training procedure involving the monitoring of specimen's free end vertical displacement with temperature. The specimen, with induced cold shape, has one end fastened in a grip, a thermocouple fixed on its surface and it is heated by a hot air gun. Specimen's deflection by SME is filmed and each vertical position of the specimen's free end is associated to a temperature value. For instance, Figure 3(b) shows specimen's free end position after heating with $140{ }^{\circ} \mathrm{C}$. 

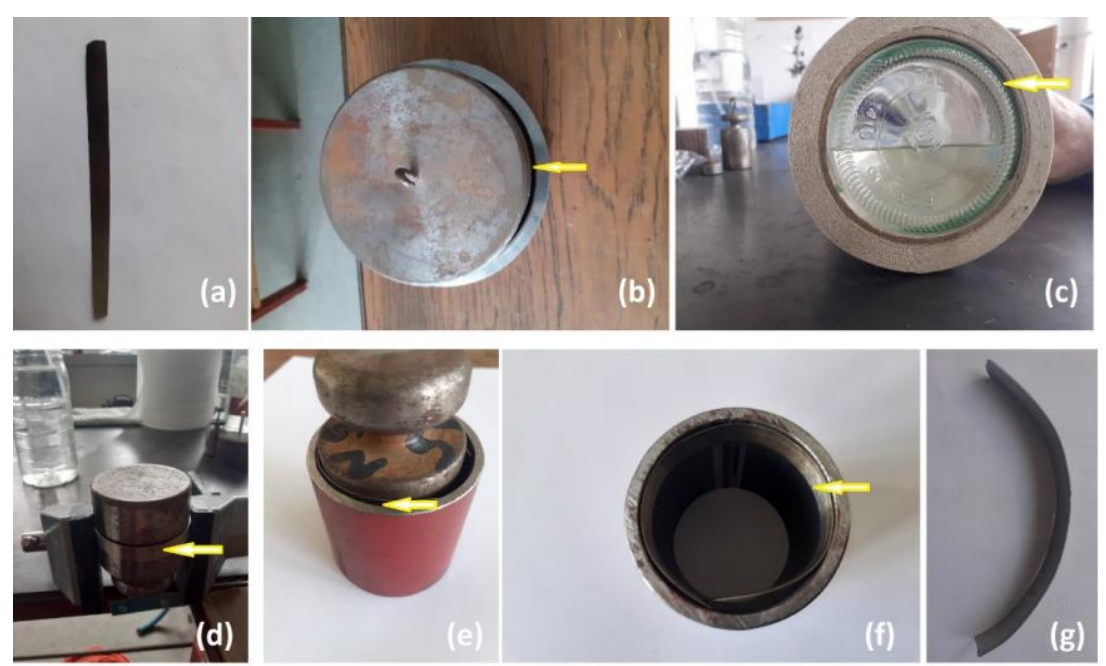

Fig. 2. Successive stages of cold shape inducing during training: (a) initial straight (hot) shape; (b) inducing the cold shape with 50 mm-radius by means of outer and inner calibers; (c) inducing the cold shape with $37.5 \mathrm{~mm}$-radius by means of outer and inner calibers; $(d)$ inducing the cold shape with 27.8 mm-radius by means of an outer caliber and a grip; (e) inducing the cold shape with 24.4 mm-radius by means of outer and inner calibers; $(f)$ inducing the cold shape with 18.4 mm-radius by means of an inner caliber; $(f)$ final cold shape

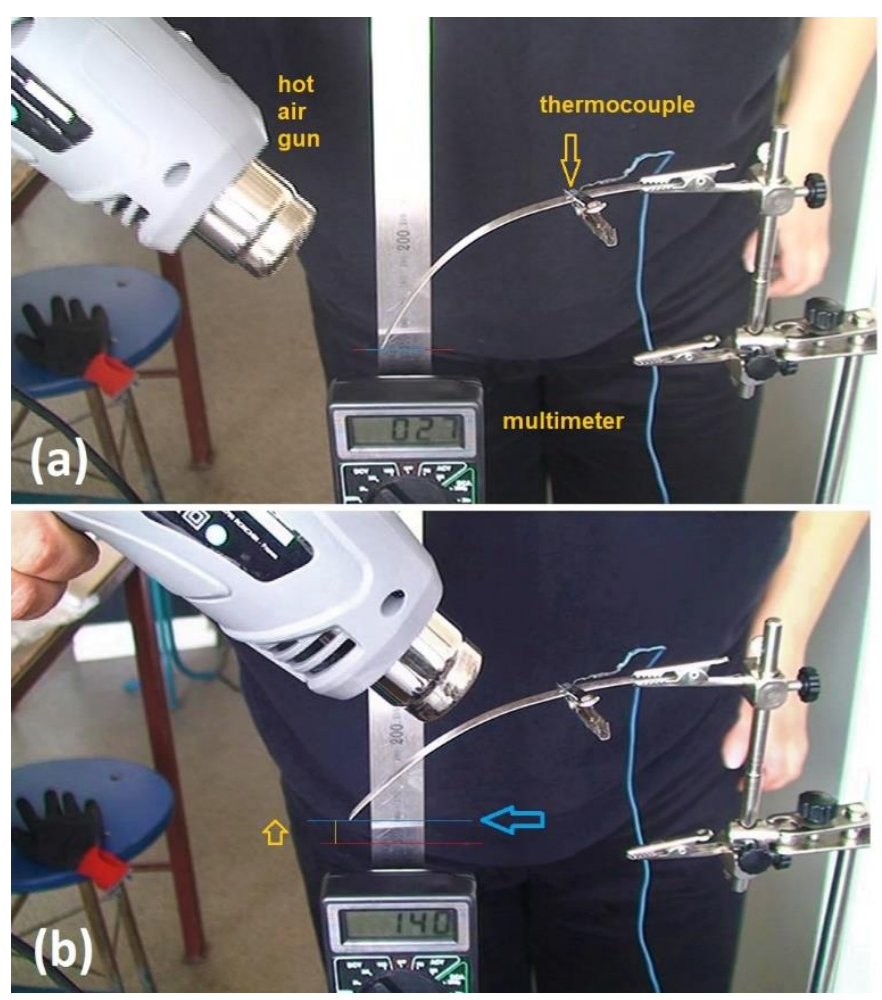

Fig. 3. Experimental stages of the training procedure by free-recovery bending shape memory effect of a PM Fe-14Mn-6Si-9Cr-5Ni (wt.\%) SMA: (a) initial stage, at RT, with the free end of the specimen with cold shape in the position marked with blue line; (b) final stage, after heating to $140^{\circ} \mathrm{C}$, when specimen's free end (marked with blue arrow) developed the displacement marked with yellow arrow 
Within the second training procedure, the specimen, with induced cold shape, is placed on a plate and heated with the hot air gun. Both cold and hot shapes have been recorded and digitalized (by means of GeoGebra software) and their chord's length (b) and circle segment height (a) have been measured and the radius was determined as:

$$
R=a / 2+b^{2} / 8 a
$$

for the cold $\left(R_{c}\right)$ and hot shapes $\left(R_{h}\right)$, in accordance with Figure 4. Finally, shape recovery degree after the bending against the $\mathrm{n}^{\text {th }}$ calibre was calculated as:

$$
\Delta_{r e c}{ }^{n}=\left(R_{h}{ }^{n}-R_{r}{ }^{n}\right) /\left(R_{h}{ }^{n-1}-R_{r}{ }^{n}\right)
$$

and the variation of $\Delta_{r e c}{ }^{n}$ with calibre's radius was discussed. In the above, $R_{h}{ }^{n-1}$ is the radius of the hot shape after specimen bending against the $n-1^{\text {th }}$ calibre.

\section{Experimental results and discussion}

\subsection{Training cycles effects on the variation of vertical free end's displacement with temperature}

Figure 5 illustrates the variations of specimen's free end displacement with temperature, for the first $\left(c_{1}\right)$ and the nineteenth training cycles $\left(c_{19}\right)$ as well as the total displacement rate. The symbols correspond to experimental values and the solid lines to second degree polynomial fits, performed by ORIGIN software.

It is noticeable that the free end's vertical position descended during training while its total stroke was maintained to about $6 \mathrm{~mm}$. Another notable aspect, from Figure 5(a) is the fact the experimental values became better fitted with the theoretical variation, in cycle 19 as compared to cycle 1. The variation of theoretical vertical displacement (d) with temperature (T) has the form:

$$
d=-3.87505 T^{2}+0.11668 T-2.70793
$$

This second order polynomial approximation has standard errors ranging between $2.29 \times 10-5$ for the coefficient of $\mathrm{T}^{2}$, and 0.1331 , for the constant that would theoretically represent the vertical displacement at $\mathrm{T}=0{ }^{\circ} \mathrm{C}$, which has no real physical interpretation.

Figure 5(b) shows that the variation of total displacement rate $(d l / d t)$ with the number of training cycles $(\mathrm{N})$, for the $1^{\text {st }}$, the $6^{\text {th }}$ and the $10^{\text {th }}$ cycle, are perfectly fitted to a second-degree polynomial, performed by ORIGIN software. The theoretical variation of displacement rate with the number of cycles has the form:

$$
d l / d t=-2.09671 N^{2}+0.00155 N+0.1955
$$

Standard error is zero for each coefficient.

\subsection{Training cycles effects on radius memory effect in bending}

Figure 6 illustrates measuring examples of the chord's length (b) and circle segment height (a), defined in Figure 4, The values are determined by GeoGebra software and they correspond to the hot and cold shapes obtained for the last three calibres.

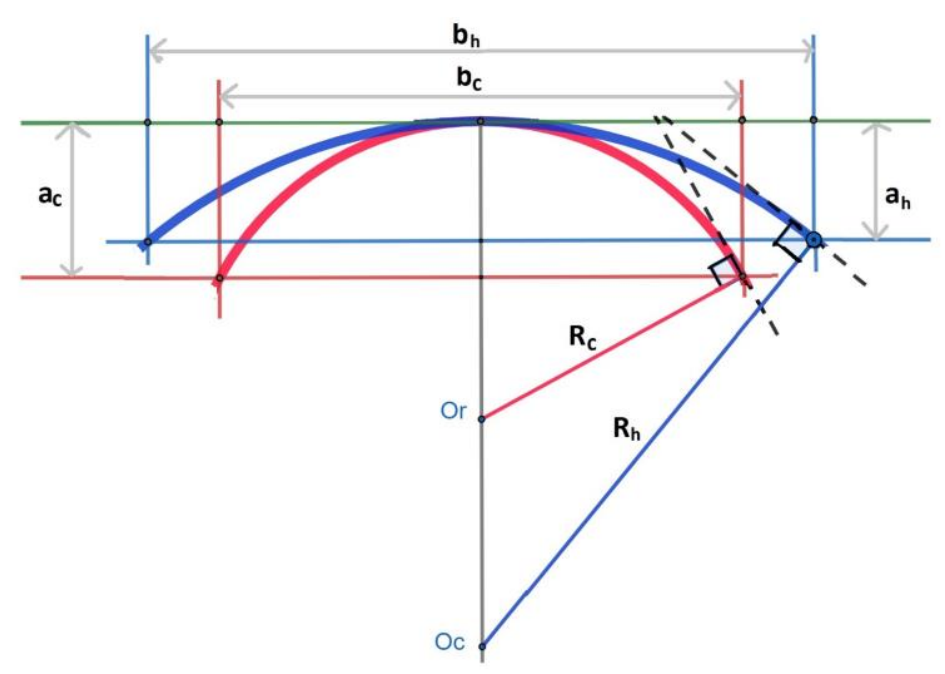

Fig. 4. Principle scheme for the measurement of circle segment height (a) and chord's length (b) for the hot $(h)$ and cold $(c)$ shapes and for determining their respective radii 

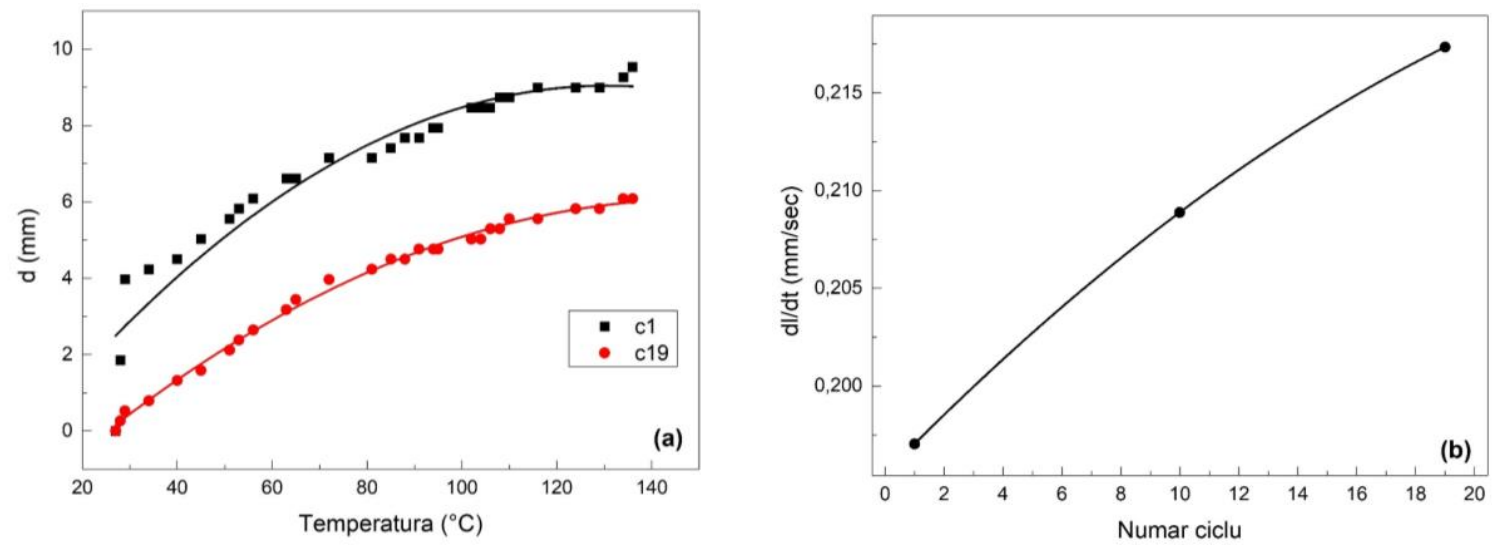

Fig. 5. Experimental (symbols) and theoretical (solid line) results obtained during the training procedure that monitors the variation of free end's displacement: (a) temperature effects in the $1^{\text {st }}$ and $19^{\text {th }}$ cycles; (b) variation of total displacement rate with the number of cycles

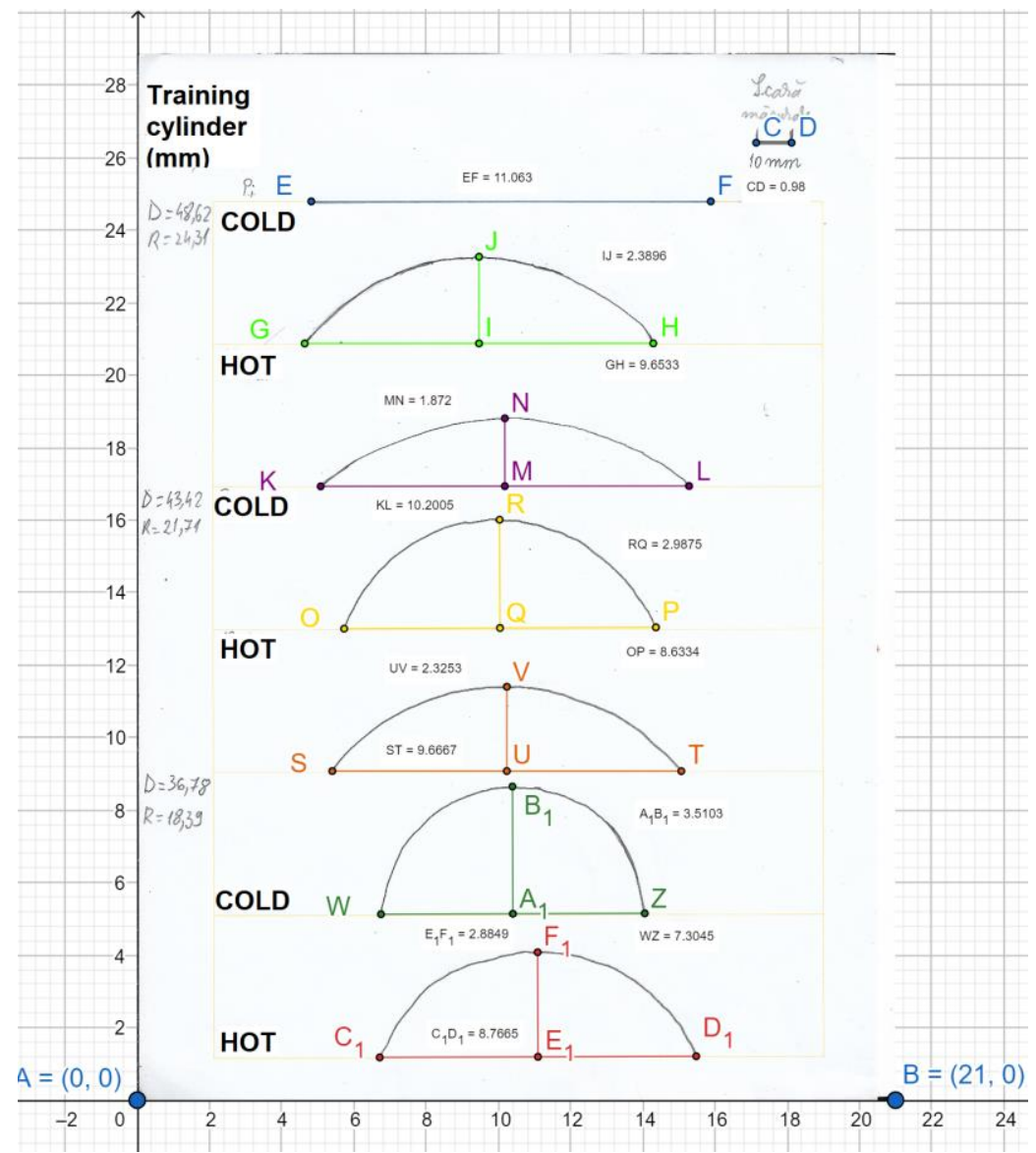

Fig. 6. Measuring examples of circle segment height and chord's length, corresponding to the first three calibers (lowest radii) from Figure 2, by means of GeoGebra software

The experimental values of specimen's radii have been calculated with eq. (1) and the values are listed in Tables 1 and 2 for the cold and hot shapes, respectively. It is noticeable that: (i) for each caliber value, $a_{\text {cold }}>a_{\text {hot }}, b_{\text {cold }}<b_{\text {hot }}$ and $R_{\text {specimen }}^{\text {expold }}<$
$R_{\text {specimen }}^{\text {exphot }}$ and (ii) due to the large elastic spring back of the specimen, in each case $R_{\text {specimen }}^{\text {exp,cold }}$ is much larger than $R_{\text {calibre }}$. 
Table 1. Experimental measurements of cold shape

\begin{tabular}{|c|c|c|c|}
\hline $\mathbf{a}$ & $\mathbf{b}$ & $\mathbf{R}_{\text {calibre }}$ & $\mathbf{R}_{\text {specimen }} \exp$ \\
\hline 17.63673 & 106.4265 & 50 & 89.09546 \\
\hline 19.09082 & 105.5857 & 37.5 & 82.54087 \\
\hline 22.4102 & 100.9582 & 27.8 & 68.05728 \\
\hline 24.38367 & 98.50306 & 24.31 & 61.93236 \\
\hline 30.58673 & 88.09592 & 21.71 & 47.0101 \\
\hline 35.81939 & 74.53571 & 18.39 & 37.29714 \\
\hline
\end{tabular}

Table 2. Experimental measurements of hot shape

\begin{tabular}{|c|c|c|c|}
\hline $\mathbf{a}$ & $\mathbf{b}$ & $\mathbf{R}_{\text {calibre }}$ & $\mathbf{R}_{\text {specimen }} \mathbf{e x p}$ \\
\hline 11.35918 & 110.6316 & 50 & 140.3653 \\
\hline 12.48469 & 110.6857 & 37.5 & 128.9058 \\
\hline 15.12653 & 108.0878 & 27.8 & 104.1069 \\
\hline 19.10204 & 104.0867 & 24.31 & 80.4469 \\
\hline 23.72755 & 98.6398 & 21.71 & 63.12175 \\
\hline 29.43776 & 89.45408 & 18.39 & 48.69749 \\
\hline
\end{tabular}

Finally, the shape recovery degree in the $\mathrm{n}^{\text {th }}$ cycle has been calculated with eq. (2).

The variation of shape recovery degree with calibre radius is shown in Figure 7 . It is noticeable that shape recovery degree varied from $44 \%$, at a calibre radius of $18.39 \mathrm{~mm}$, to $80 \%$ at a calibre radius of $37.5 \mathrm{~mm}$. This evolution is rather expectable, if one considers that the specimen was subjected to a larger and larger deformation degree, thus accumulating more and more permanent deformation.

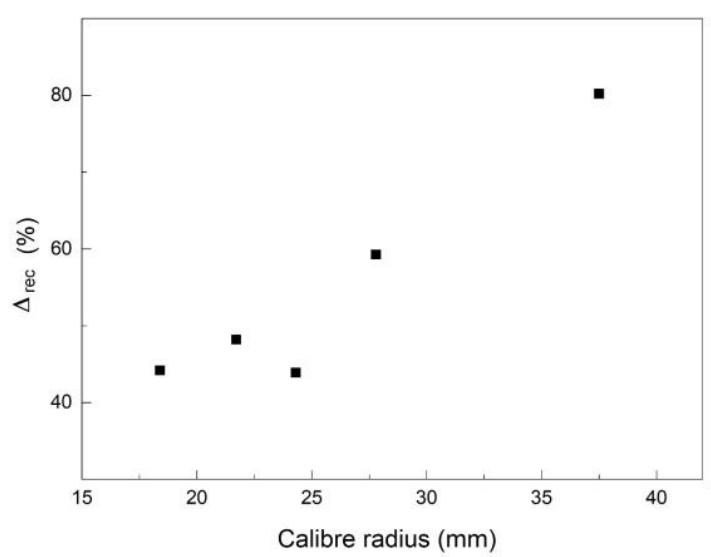

Fig. 7. Variation of experimental values of recovery degree with the caliber radius

\section{Conclusions}

The main conclusions are the following:

- the variation of vertical free end's displacement with temperature, during the training cycles, came closer to a second order polynomial fit under the form:

$$
d=-3.87505 T^{2}+0.11668 T-2.70793
$$

- the variation of vertical displacement rate with the number of cycles was fitted under the form:

$$
d l / d t=-2.09671 N^{2}+0.00155 N+0.1955
$$

- with decreasing the radius of the caliber used for cold shape induction, from 37.5 to $18.39 \mathrm{~mm}$, the shape recovery degree decreased from 80 to $44 \%$, as an effect of the accumulating of permanent deformation.

\section{References}

[1]. Sun L., Huang M., Ding Z., Zhao Y., Wang C. C., Purnawali H., Tang C., Stimulus-responsive shape memory materials: A review, Materials \& Design, 33, p. 577-640, 2012. [2]. Wilhelm E., Richter C., Rapp B. E., Phase change materials in microactuators: Basics, applications and perspectives, Sensor Act. A 271, p. 303-347, 2018.

[3]. Chang L. C., Read T. A., Plastic deformation and diffusionless phase changes in metals - The gold cadmium beta phase, Trans. AlME, 189, Journal of Metals, p. 47-52, 1951.

[4]. Lieberman D. S., Schmerling M. A., Karz R. W., Ferroelastic "memory" and mechanical properties in GoldCadmium, in Shape memory Effects in Alloys, J. Perkins, ed., Plenum Press, New York, p. 203-244, 1977.

[5]. Wayman C. M., Duerig T. W., An introduction to martensite and shape memory, in: Engineering Aspects of Shape Memory Alloys, T. W. Duerig, K. N. Melton, D. Stockel, C. M. Wayman, Eds., Butterworth-Heinemann, Oxford, p. 3-20, 1990.

[6]. Tanaka Y., Himuro Y., Kainuma R., Sutou Y., Omori T., Ishida K., Ferrous Polycrystalline Shape-Memory Alloy Showing Huge Superelasticity, Science, 327, p. 1488-1490, https://doi.org/10.1126/science.1183169, 2010.

[7]. Omori T., Ando K., Okano M., Xu X., Tanaka Y., Ohnuma I., Kainuma R., Ishida K., Superelastic Effect in Polycrystalline Ferrous Alloys, Science, 333, p 68-71, https://doi.org/10.1126/science.1202232, 2011.

[8]. Chernenko V. A., Barandiarán J. M., Preface, in: Advances in Shape Memory Materials. Ferromagnetic Shape Memory Alloys, V.A. Chernenko Ed., Trans Tech Publications, 635, p. 1, doi: 10.4028/www.scientific.net/MSF.635.0, 2010.

[9]. Dunne D., Shape memory in ferrous alloys, in: Phase Transformations in Steels. Vol 2 Diffusionless Transformations, High Strength Steels, Modelling and Advanced Analytical Techniques, E. Pereloma and D.V. Edmonds, Eds., Woodhead Publishing, Cambridge, p. 83-125, 2012.

[10]. Otsuka H., Yamada H., Maruyama T., Matsuda S., Murakami, Effects of Alloying Additions on Fe-Mn-Si Shape Memory Alloys, ISIJ Int, 30, p. 674-679, 1990.

[11]. Moriya Y., Kimura H., Ishizaki S., Hashizume S., Suzuki S., Suzuki H., Sampei T., Properties of Fe-Cr-Ni-Mn-Si (-Co) shape memory alloys, J Phys IV, France 01 C4, p. 433-437, 1991. [12]. Peng H., Wang G., Wang S., Chen J., Mac Laren I., Wen Y., Key criterion for achieving giant recovery strains in polycrystalline $\mathrm{Fe}-\mathrm{Mn}$-Si based shape memory alloys, Mater. Sci. Eng. A., 712, p. 37-49, doi: 10.1016/j.msea.2017.11.071, 2018.

[13]. Spiridon I.-P., Lohan N.-M., Suru M.-G., Mihalache E., Bujoreanu L.-G., Pricop B., A study of free recovery in a $\mathrm{Fe}-\mathrm{Mn}$ $\mathrm{Si}$-Cr shape memory alloy, Metal Science and Heat Treatment, 57(9-10), p. 548-552, doi: 10.1007/s11041-016-9920-z, 2016. 


\section{THE ANNALS OF "DUNAREA DE JOS" UNIVERSITY OF GALATI \\ FASCICLE IX. METALLURGY AND MATERIALS SCIENCE \\ $\mathrm{N}^{\circ} .3$ - 2021, ISSN 2668-4748; e-ISSN 2668-4756 \\ Article DOI: https://doi.org/10.35219/mms.2021.3.01}

[14]. Pricop B., Soyler A. U., Ozkal B., Bujoreanu L. G., Powder Metallurgy: An Alternative for FeMnSiCrNi Shape Memory Alloys Processing, Front. Mater., 7, 247 doi: https://doi.org/10.3389/fmats.2020.00247, 2020.

[15]. Pricop B., Söyler U., Özkal B., Lohan N. M., Paraschiv A. L., Suru M. G., Bujoreanu L.-G., Influence of Mechanical Alloying on the Behavior of Fe-Mn-Si-Cr-Ni Shape Memory Alloys Made by Powder Metallurgy, Materials Science Forum, 739, p. 237-241, 2013.

[16]. Chen S. C., Chuang C. Y., Yan C. L., Hsu T. L., Effect of fcc antiferromagnetism on martensitic transformation in $\mathrm{Fe}-\mathrm{Mn}$-Si based alloy, Mater. Sci. Eng. 264, p. 262-268, https://doi.org/10.1016/S0921-5093(98)01105-8, 1999.

[17]. Ciurca L., Lohan N.-M., Pricop B., Bujoreanu L. G., Study of tensile behaviour of $\mathrm{Fe}$ base shape memory alloys during mechanical cycling, IOP Conf. Ser.: Mater. Sci. Eng. 591, 012009, doi:10.1088/1757-899X/591/1/012009, 2019.

[18]. Pricop B., Mihalache E., Stoian G., Borza F., Özkal B., Bujoreanu L.-G., Thermo-mechanical effects caused by martensite formation in powder metallurgy $\mathrm{FeMnSiCrNi}$ shape memory alloys, Powder Met., 61(4), p. 348-356, doi: 10.1080/00325899.2018.1492773, 2018. 